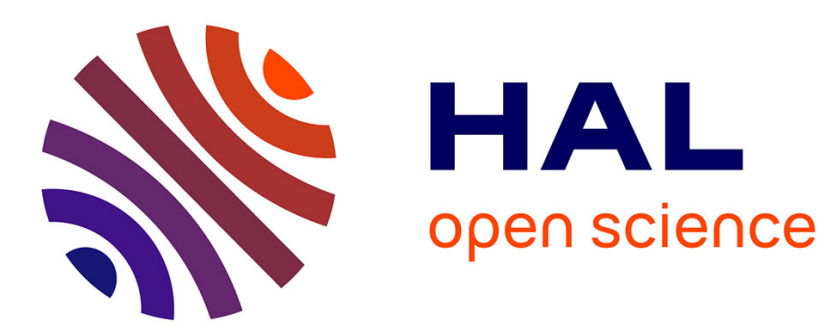

\title{
Prediction of the sound field into high-rise building facades due to its balcony ceiling form
}

Hany Hossam Eldien, Philippe Woloszyn

\section{To cite this version:}

Hany Hossam Eldien, Philippe Woloszyn. Prediction of the sound field into high-rise building facades due to its balcony ceiling form. Applied Acoustics, 2004, 65, pp.431. 10.1016/j.apacoust.2003.11.002 . hal-01555290

\author{
HAL Id: hal-01555290 \\ https://hal.science/hal-01555290
}

Submitted on 3 Jul 2017

HAL is a multi-disciplinary open access archive for the deposit and dissemination of scientific research documents, whether they are published or not. The documents may come from teaching and research institutions in France or abroad, or from public or private research centers.
L'archive ouverte pluridisciplinaire HAL, est destinée au dépôt et à la diffusion de documents scientifiques de niveau recherche, publiés ou non, émanant des établissements d'enseignement et de recherche français ou étrangers, des laboratoires publics ou privés. 


\section{ResearchGate}

See discussions, stats, and author profiles for this publication at:

https://www.researchgate.net/publication/243350666

\section{Prediction of the sound field into high-rise building facades due to its balcony ceiling form}

Article in Applied Acoustics · April 2004

DOI: 10.1016/j.apacoust.2003.11.002

CITATIONS

37

2 authors:

\section{H. Hossam Eldien}

University of Dammam

35 PUBLICATIONS 105 CITATIONS

SEE PROFILE
READS

22

\section{Philippe Woloszyn}

French National Centre for Sci...

100 PUBLICATIONS 209 CITATIONS

SEE PROFILE

Some of the authors of this publication are also working on these related projects:

Project HAUP HyperAmbiotopes Urbains Participatifs View project

All content following this page was uploaded by H. Hossam Eldien on 02 February 2016. 


\title{
Technical note \\ Prediction of the sound field into high-rise building facades due to its balcony ceiling form
}

\author{
H. Hossam El Dien*, P. Woloszyn \\ CERMA, UMR CNRS 1563, Ecole d'Architecture de Nantes, Rue Massenet, BP 81931-44319, \\ Nantes cedex 3, France
}

Received 1 July 2003; received in revised form 28 October 2003; accepted 5 November 2003

\begin{abstract}
This study presents the acoustic performance off tall building facades closed to roadway due to one of balcony configurations, namely ceiling, with an inclined form in terms of traffic noise reduction. Three inclined angles are tested $\left(5,10\right.$, and $\left.15^{\circ}\right)$ with different balcony depths by using a Pyramid Tracing model developed by A. Farina. The results in terms of A-weighted sound pressure level reduction are expressed in free field into the balcony back wall. The protection level, defined as the difference in noise levels before and after inserting the proposed balcony form, has been used to assess the reduction offered by that configuration. A maximum reduction due to using these forms is obtained at higher floors and at balcony of $2 \mathrm{~m}$ depths and more. As a consequence of simulation results, it is found that the prediction of protection levels from 10th to 15 th floor can be calculated from an empirical equation.

(C) 2003 Elsevier Ltd. All rights reserved.
\end{abstract}

Keywords: Environmental noise; Balcony; Pyramid Tracing; Traffic noise

\section{Introduction}

A balcony is an extension of an internal floor with access by means of windows or doors to an external environment. It provides view and weather protection and is a building familiar element. In particular, it can provide an acoustical protection by means of its elements forms.

Most of the previous studies investigated sound levels on balconies by using experimental models as the work of Mohsen, and Oldham [1], numerical models of Hothersall [2], and Li [3], and the field measurements analysed by May [4], Gilbert

* Corresponding author. Tel.: +33-2-40-59-43-24; fax: +33-2-40-59-11-77.

E-mail address: hany.hossam@cerma.archi.fr (H. Hossam El Dien). 
[5], and Li [3]. These studies carried out a study of traffic noise reduction in the context of treatment to the sound source, in the path between the sound source and the receiver, and at the reception point.

An alternative approach concerning the self-protecting buildings was discussed by Mohsen and Oldham by means of changing balcony depth [1]. Another architectural concept was presented by Hossam El-dien and Woloszyn [6,7], by using an inclined parapet to increase the shielding effect to protect the balcony back wall from the traffic noise nuisance in a free field.

In the present study, we aim to predict the effect of one of the balcony configurations, namely ceiling, on the traffic noise reduction into building facades.

Inclined ceilings with different angles are tested by a 3D numerical model of Pyramid tracing developed by Farina shown in Fig. 1 [8], and in free field conditions.

The results will be expressed in terms of sound pressure level reduction, in A-weighted scale, into the balcony back wall and for a high rise building.

\section{Geometric parameters}

Acoustic simulation programs (CITYMAP\&DISIAPYR) are used to model the outdoor sound propagation environment within the balcony configurations and in

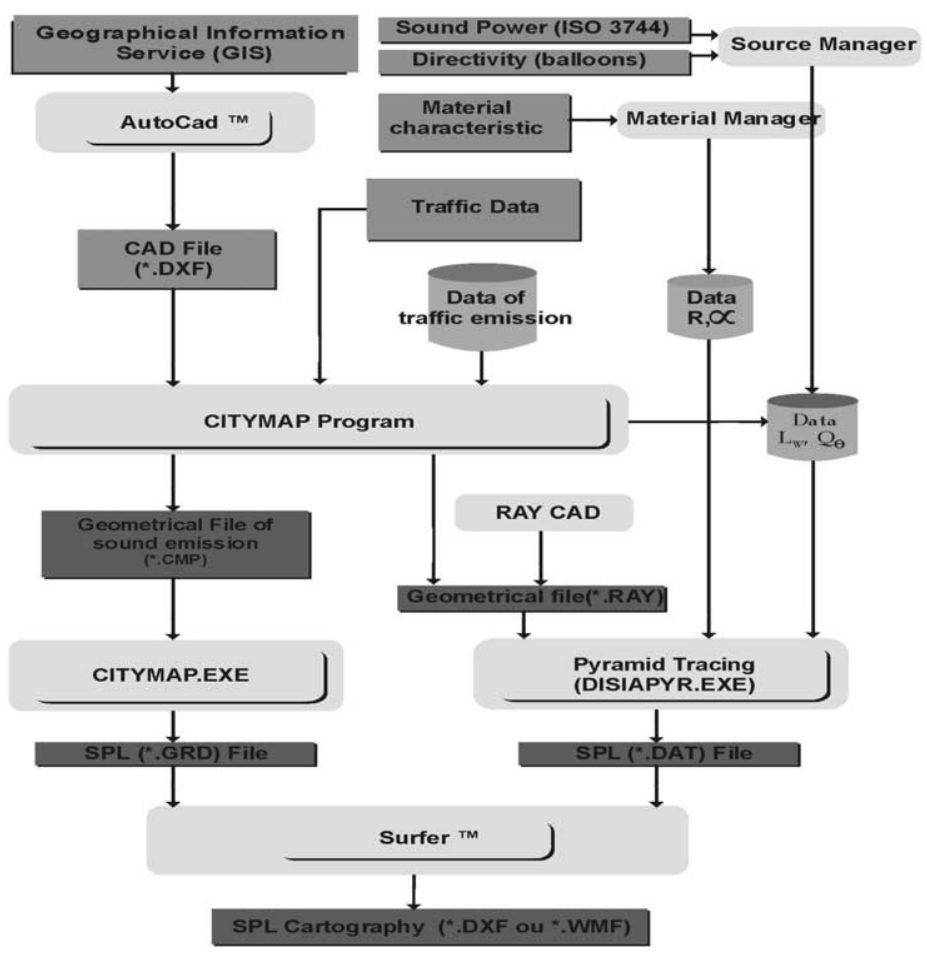

Fig. 1. Schematic representation of the pyramid tracing model (DISIPYR). 
three dimensions. This algorithm allows the simulation of outdoor sound propagation with a complex urban form and the evaluation of sound passing through sound insulating panels, taking into account the edge diffraction over the boundaries and the scattering of sound from the edges of finite surfaces, and the surface diffusion coefficient [9].

As shown in Fig. 2, the simulation has been carried out with the following variables:

1. The horizontal projection depth $(\mathrm{W}=1,2$, and $3 \mathrm{~m})$.

2. The balcony's ceiling inclined angle $\left(\varnothing=5,10\right.$, and $\left.15^{\circ}\right)$.

And we have fixed the following parameters:

1. Sound source (infinite).

2. Distance to road $(8.00 \mathrm{~m})$.

3. Front wall height $(1.00 \mathrm{~m})$.

4. Balcony's length $(5.00 \mathrm{~m})$.

5. Number of floors (17 floors).

\section{Prediction methodology}

In three dimensions, the model is equivalent to an infinite coherent line source parallel to the building facade. All the surfaces in the model are initially defined as specular surfaces (concrete with absorption coefficient 0.07 at $1 \mathrm{KHz}$ ). The acoustic performance of the balcony ceiling with an inclined shape has been assessed by
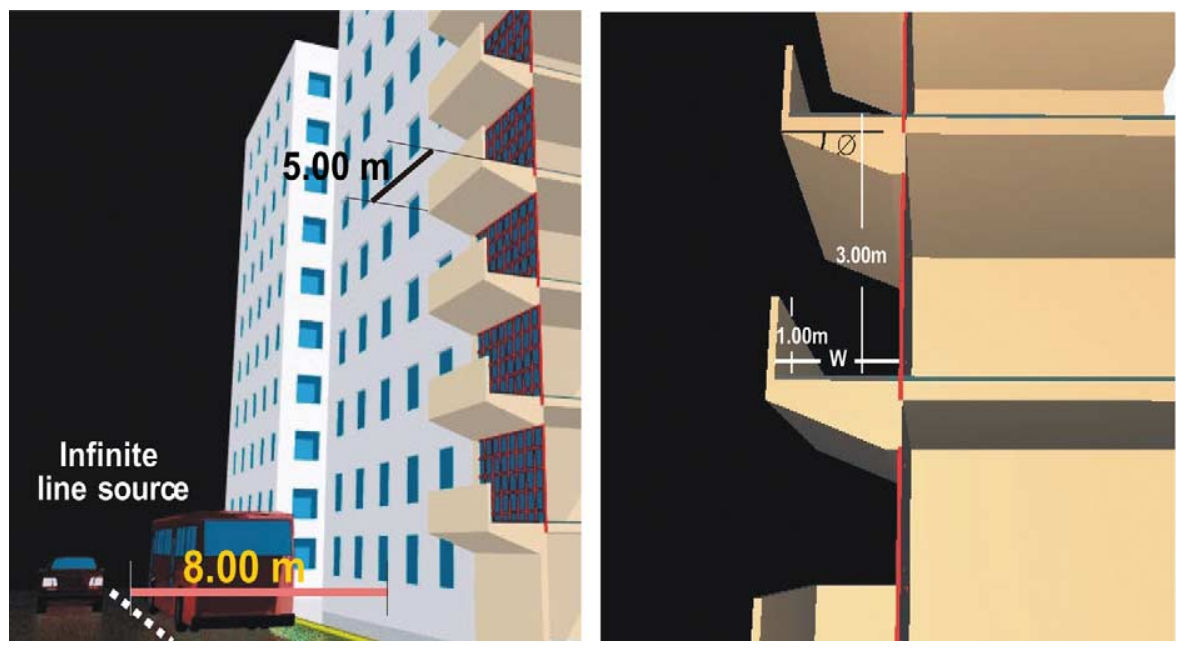

Fig. 2. Geometric parameters. 

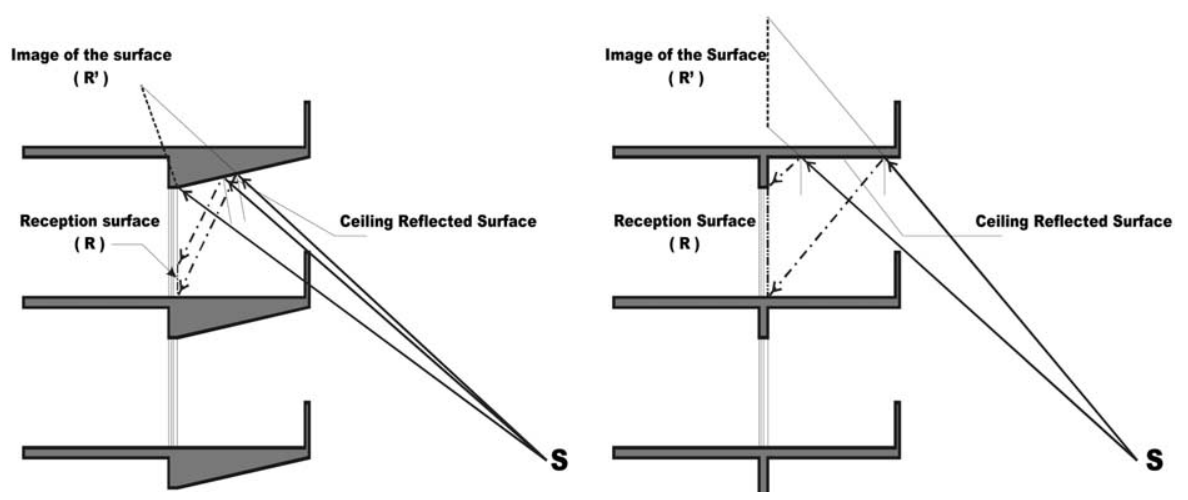

Fig. 3. Schematic representation of the reception surface and its image before and after changing balcony ceiling form.

means of a numerical simulation. Three inclined angles have been tested $(5,10$, and $15^{\circ}$.

The basic concept of inclining the balcony ceiling is to decrease the power of reflection and diffuse energy components by changing the direction of reflected rays away from the openings located at the balcony back wall as shown in Fig. 3. In the case of the inclined ceiling, we can notice that the protected surface over the balcony back wall increases by comparison of the protected surface gained from the classical form as a consequence of ceiling reflected area.

Firstly, the sound pressure reference level $\left(\mathrm{SPL}_{r e f}\right)$, was calculated over the balcony back wall with an inclined angle $\boldsymbol{\varnothing}$ equal to $0^{\circ}$ through 3000 reception points over the back wall.

The protection level is defined as the difference in noise level at an assessment point with and without changing ceiling inclined angle, and is calculated according to the following equation:

$$
\mathrm{L}_{p}=\mathrm{SPL}_{r e f}-\mathrm{SPL}_{\theta} \quad \mathrm{dB}(\mathrm{A})
$$

where $\mathrm{SPL}_{r e f}$ is the reference level and $\mathrm{SPL}_{\varnothing}$ is the sound pressure level calculated for a given ceiling angle at the same point.

\section{Simulation results}

\subsection{Balcony with $1 \mathrm{~m}$ depth}

In this part of investigation, the acoustic performance of inclined ceiling form and for a closed balcony with $1 \mathrm{~m}$ depth is simulated. Fig. 4 shows the average reduction of sound level obtained by three types of inclined ceiling forms. It was found that the protection gained at the lower levels is not noticeable as a result of the direct component effect. The effect of these forms can be observed from the fourth level, and 
reaches to its maximum value at the 16th level (Fig. 4), where protection gain is $2 \mathrm{~dB}$ (A).

Generally, the performance of 10 and $15^{\circ}$ angles are more effective than $5^{\circ}$ angle, and the gain obtained is from 0.5 to $2 \mathrm{~dB}(\mathrm{~A})$ in terms of sound level reduction.

Through studying each floor level, we can notice that the increase of protection values from 10th to 15 th floor can be ordered (Fig. 5). It was found that the predicted protection values for these configurations can be calculated according to the following exponential equation:

$$
\mathrm{L}_{p}=\left(\left(2.40+0.2\left(\mathbf{n}_{i}-\mathbf{n}_{o}\right)\right) \tan \boldsymbol{\varnothing}+0.20\right) \mathrm{e}^{-1.85 h} / \tan \varnothing \mathrm{dB}(\mathrm{A}), 15 \geqslant n_{i} \geqslant 10
$$

where $\mathbf{n}_{i}$ is floor number, $\mathbf{n}_{\boldsymbol{o}}=10, \mathbf{h}$ is the height above the balcony floor, and $\boldsymbol{\varnothing}$ is ceiling inclined angle.

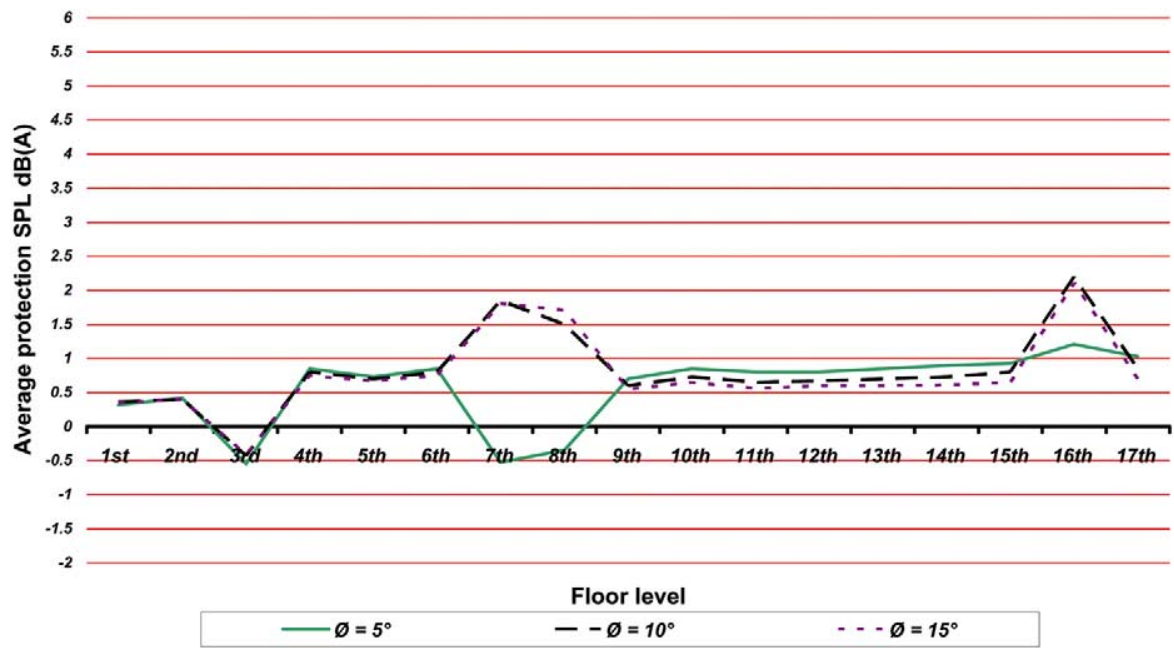

Fig. 4. Average of protection offered by inclined ceilings of a balcony with $1 \mathrm{~m}$ depth.

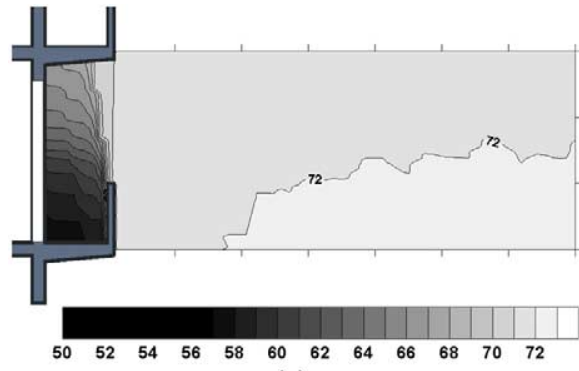

(a)

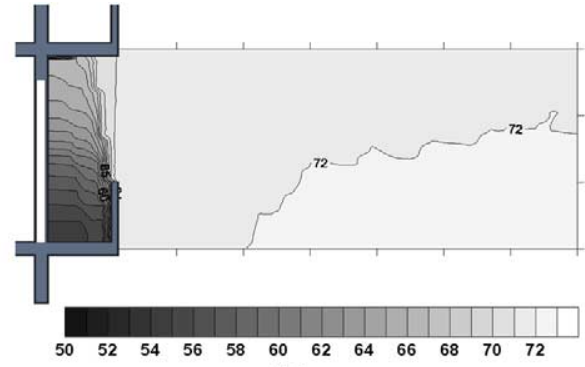

(b)

Fig. 5. Balcony cross section shows the maximum effect of the inclined ceiling, for a balcony with $1 \mathrm{~m}$ depth, and with an angle equal to $5^{\circ}$ (a), and the classical ceiling form (b) at the 16 th floor. 


\subsection{Balcony with $2 \mathrm{~m}$ depth}

By using the same method, the acoustic performance of inclined ceilings for a closed balcony with $2 \mathrm{~m}$ depth was tested. Figs. 6 and 7 shows the average of sound level reduction obtained for three angles for that configuration. The average reduction obtained at the lower levels is negligible by comparison of that obtained from 1 $\mathrm{m}$ balcony depth, while it increases at the higher floors. The reduction is negative

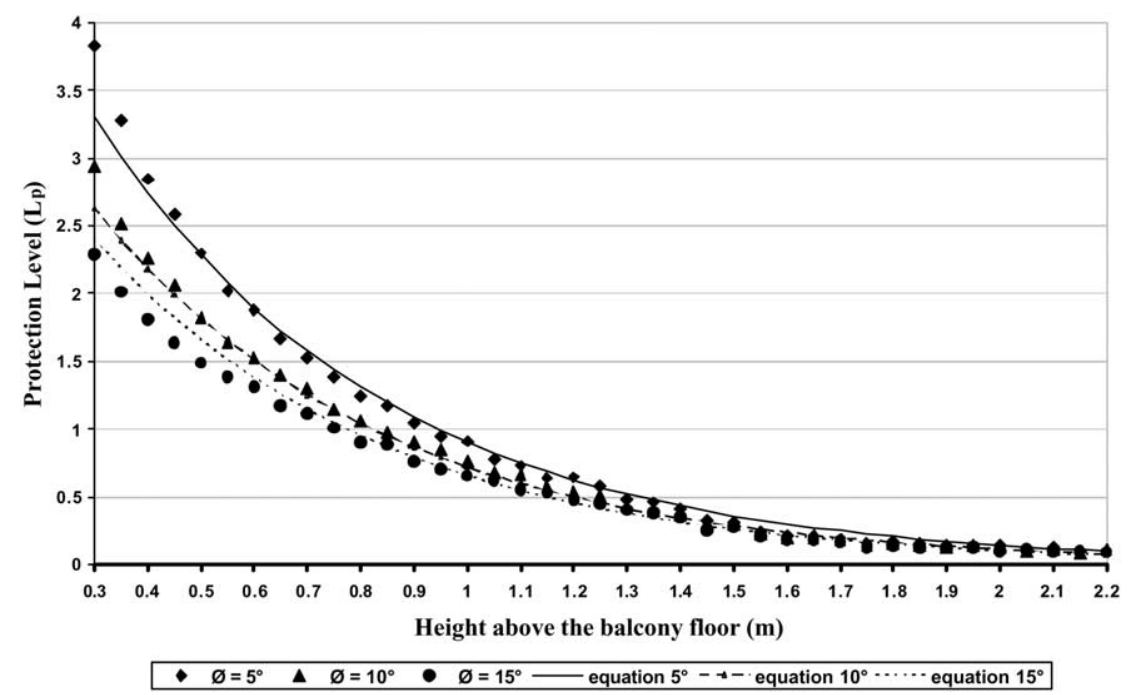

Fig. 6. Protection values provided at the centre of the balcony back wall with $1 \mathrm{~m}$ depth, numerical simulation (Dots), and empirical equation (Lines) at the 15 th floors and for angles $\varnothing=5,10$, and $15^{\circ}$.

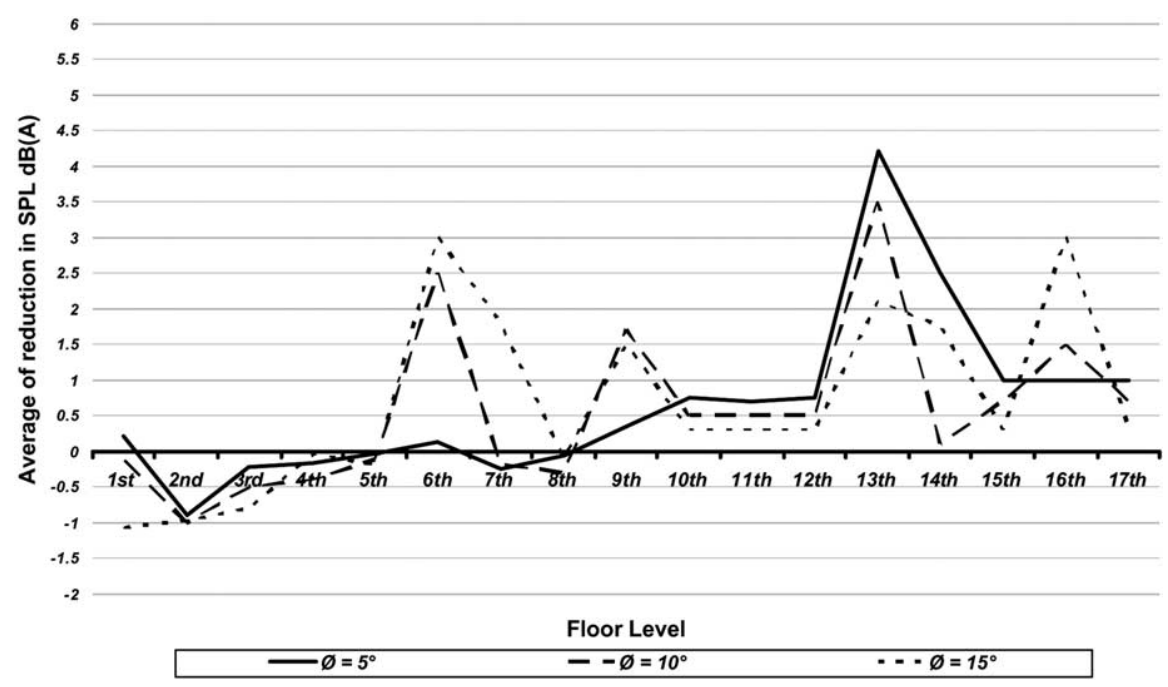

Fig. 7. Average of protection offered by inclined ceilings of a balcony with $2 \mathrm{~m}$ depth. 
from the 1st to 5th floor while it increases from the 6th floor and reaches to its maximum value at the 13 th floor (Fig. 8). Generally that form allows more benefits than that of $1 \mathrm{~m}$ balcony depth. Ten and $15^{\circ}$ angles are more effective at lower levels, while $5^{\circ}$ angle has a greater effect at higher levels. Furthermore, this configuration allows a protection level from 0.5 to $4 \mathrm{~dB}$ (A).

Similar to $1 \mathrm{~m}$ balcony depth, it is observed that protection values from the 10th floor to the 15th floor regularly increase except for the 13th floor (maximum value), and the 14 th floor for the angle $\varnothing$ equal to $10^{\circ}$.

We found that protection predicted values for these floors and for these configurations can be calculated according to the following exponential equation:

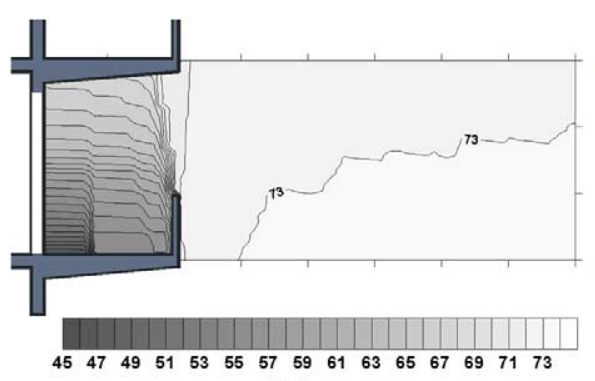

(a)

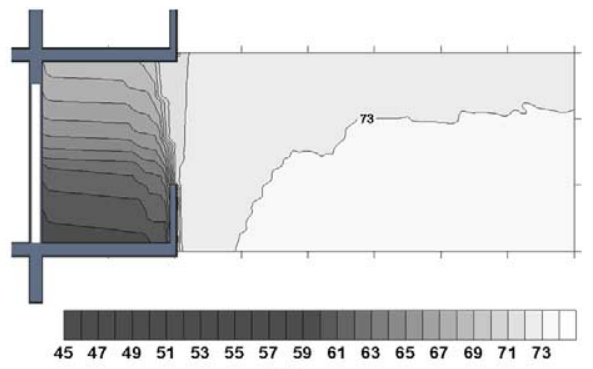

(b)

Fig. 8. Balcony cross section shows the maximum effect of the inclined ceiling, for a balcony with $2 \mathrm{~m}$ depth, and with an angle equal to $5^{\circ}$ (a), and the classical ceiling form (b) at the 13th floor, and at the reception surface.

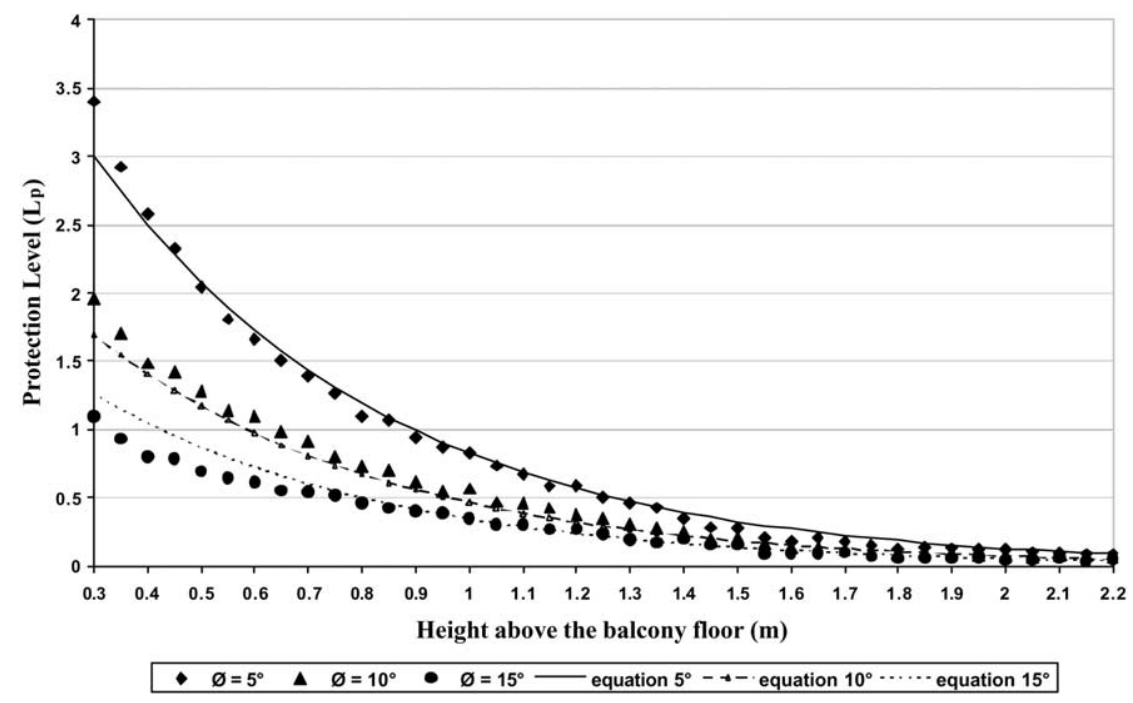

Fig. 9. Protection values provided at the centre of the balcony back wall with $2 \mathrm{~m}$ depth, numerical simulation (Dots), and empirical equation (Lines) at the 15 th floors and for angles $\varnothing=5,10$, and $15^{\circ}$. 


$$
\mathrm{L}_{p}=\left(\left(0.25+0.1\left(\mathbf{n}_{i}-\mathbf{n}_{o}\right)\right) \tan \boldsymbol{\varnothing}+0.40\right) \mathrm{e}^{-1.85 h} / \tan \varnothing \mathrm{dB}(\mathrm{A}), 15 \geqslant n_{i} \geqslant 10 .
$$

where $\mathbf{n}_{i}$ is floor number, $\mathbf{n}_{\boldsymbol{o}}=10, \mathbf{h}$ is the height above the balcony floor, and $\boldsymbol{\varnothing}$ is ceiling inclined angle (Fig. 9).

\subsection{Balcony with $3 \mathrm{~m}$ depth}

Acoustic performance of inclined ceilings for a closed balcony with $3 \mathrm{~m}$ depth provides more reduction at lower levels than that obtained from the previous configurations and also for higher levels. The average reduction obtained at the lower floors is more effective than the other two previous forms, and also for the higher floors. Reduction values are negative at the first two floors and begin to increase from the 3 rd floor to reach its maximum value at the 11 th floor (Figs. 10 and 11). In

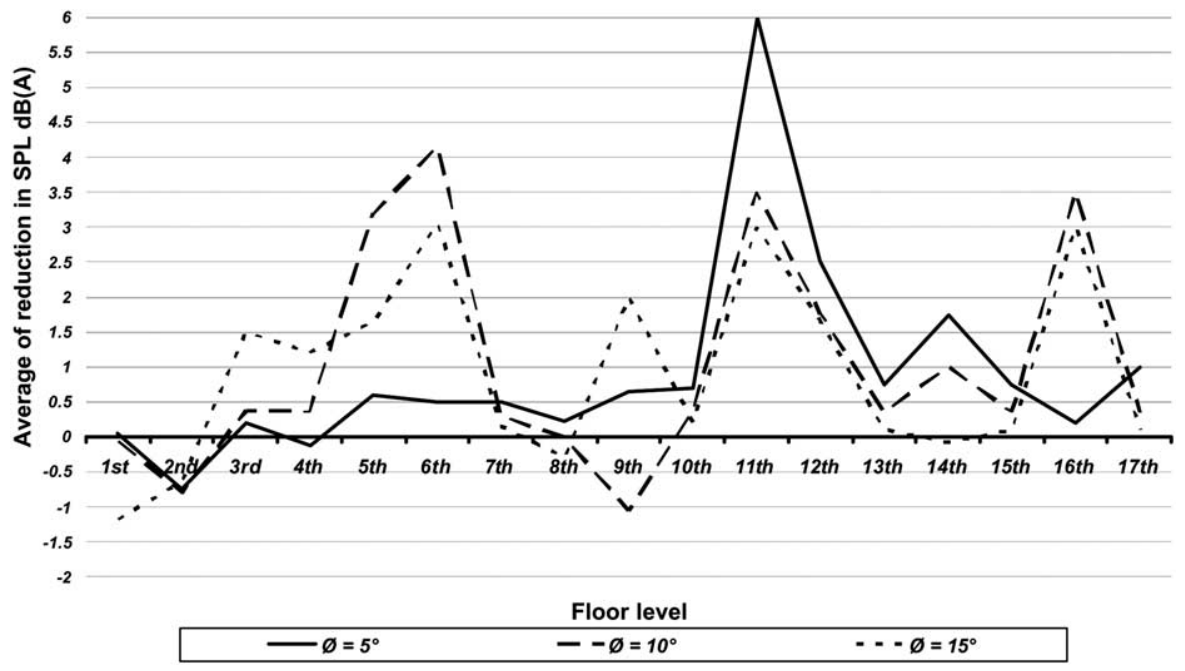

Fig. 10. Average of protection offered by inclined ceilings of a balcony with $3 \mathrm{~m}$ depth.

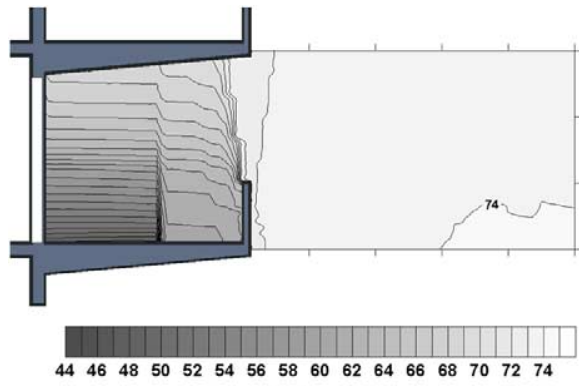

(a)

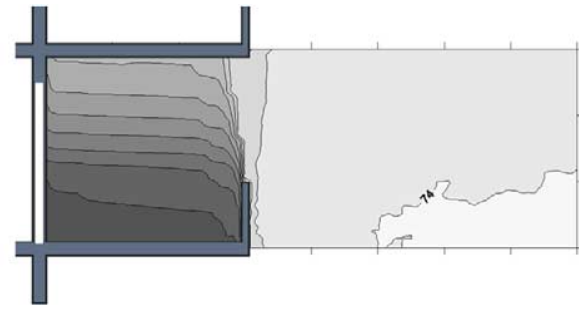

$\begin{array}{llllllllllllllll}44 & 46 & 48 & 50 & 52 & 54 & 56 & 58 & 60 & 62 & 64 & 66 & 68 & 70 & 72 & 74\end{array}$

(b)

Fig. 11. Balcony cross section shows the maximum effect of the inclined ceiling, for a balcony with $3 \mathrm{~m}$ depth, and with an angle equal to $5^{\circ}$ (a), and the classical ceiling form (b) at the 11 th floor. 


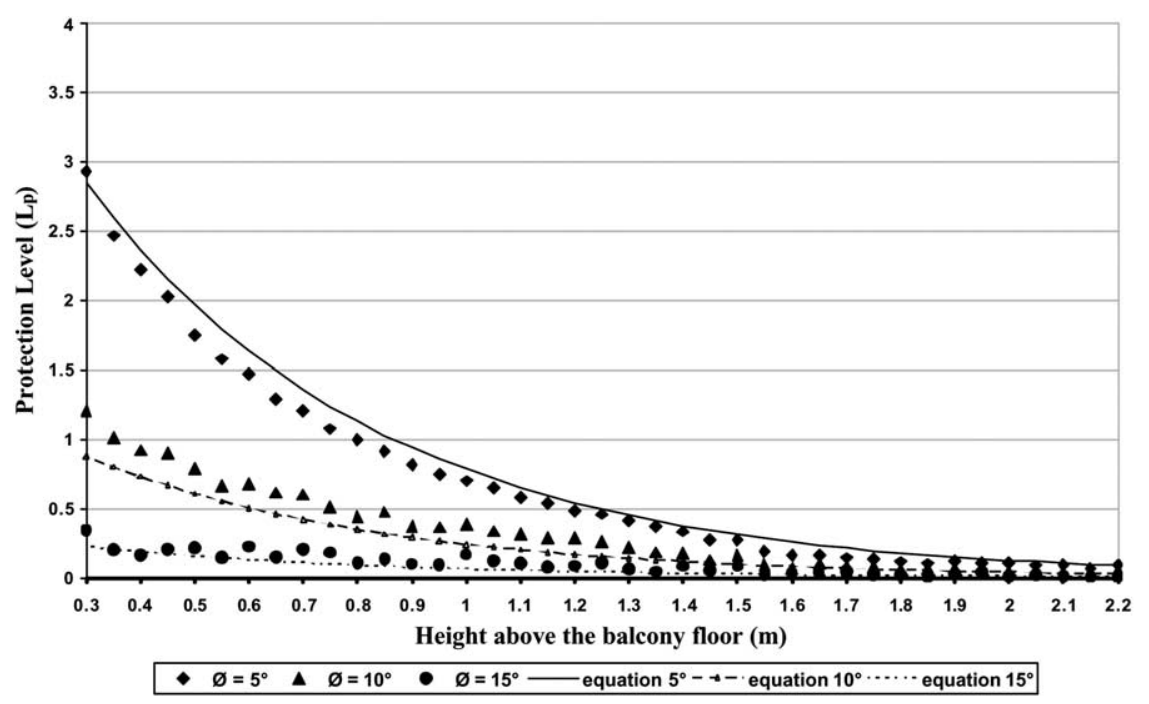

Fig. 12. The protection values offered at the centre of the balcony back wall with $3 \mathrm{~m}$ depth, numerical simulation (Dots), and empirical equation (Lines) at the 15 th floors and for angles $\varnothing=5,10$, and $15^{\circ}$.

general, the average protection gained from that configuration is from 0.5 to $6 \mathrm{~dB}$ (A).

In accordance with the previous forms, the protection values increase from the $10^{\text {th }}$ floor to the 15 th floor except for the 11 th floor (maximum value) and the 12 th floor. They can be calculated according to the following exponential equation:

$$
\mathrm{L}_{p}=\left(\left(-0.75+0.05\left(\mathbf{n}_{i}-\mathbf{n}_{o}\right)\right) \tan \boldsymbol{\varnothing}+0.60\right) \mathrm{e}^{-1.85 h} / \tan \emptyset \mathrm{dB}(\mathrm{A}), 15 \geqslant n_{i} \geqslant 10 .
$$

except for the 12 th floor where it can be calculated using the following equation:

$$
\mathrm{L}_{p}=\left(\left(-1.75+0.05\left(\mathbf{n}_{i}-\mathbf{n}_{o}\right)\right) \tan \emptyset+0.60\right) \mathrm{e}^{-1.85 h} / \tan \boldsymbol{\varnothing} \mathrm{dB}(\mathrm{A}), n_{i}=12 .
$$

where $\mathbf{n}_{i}$ is floor number, $\mathbf{n}_{o}=10, \mathbf{h}$ is the height above the balcony floor, and $\boldsymbol{\emptyset}$ is ceiling inclined angle (Fig. 12).

For these configurations, Eqs. (1), (2), and (3) lead to predict the protection level $\mathbf{L}_{p w}$ as a relation with the balcony depth can be calculated as the following relation:

$$
\boldsymbol{L}_{p w}=\left(\left(4.45-2.075 \mathbf{w}+0.4^{-0.70 \mathbf{w}}\left(\mathbf{n}_{i}-\mathbf{n}_{o}\right)\right) \tan \boldsymbol{\emptyset}+0.40\right) \mathrm{e}^{-1.85 h} / \tan \boldsymbol{\varnothing d B}(\mathrm{A})
$$

where $\mathbf{w}$ is balcony depth, $\mathbf{n}_{i}$ is floor number $\left(15 \geqslant n_{i} \geqslant 10\right), \mathbf{n}_{o}=10, \boldsymbol{h}$ is the height above the balcony floor, and $\varnothing$ is ceiling inclined angle. 


\section{Conclusion}

The Pyramid Tracing model was used to predict the performance of a balcony ceiling with inclined form. The average noise reduction provided by that configuration with reflective surface was about $0.5-6 \mathrm{db}(\mathrm{A})$. This investigation showed that the inclined ceiling form can dominate the sound reflected from its bottom surface with changing the reflected ray direction away from a balcony back wall.

Reduction benefits are in direct proportion to both floor level and balcony depth. On the other hand, they are inversely proportional to the ceiling inclined angle at higher floors, and are directly proportional to the ceiling inclined angles at lower floors. Generally, the predicted results showed that a balcony ceiling form can be employed to protect weak points on the facades, for high rise buildings, against traffic noise propagation. In addition, results of this investigation will hopefully provide practical information to the architect who wishes to design facades which can be described as self protected with respect to the external acoustic environment. It will be seen that a slight modification of existing building envelope design can provide additional sound protection without compromising other environmental requirements. Further work will be undertaken to validate these results by means of experimental study.

\section{References}

[1] Mohsen EA, Oldham DJ. Traffic noise reduction due to the screening effect of balconies on a building façade. Applied Acoustics 1977;10:243-57.

[2] Hothersall DC, Horoshenkov KV, Mercy SE. Numerical modelling of the sound field near a tall building with balconies near a road. Journal of Sound and Vibration 1996;198(4):507-15.

[3] Li KM, Lui WK, Lau KK, Chan KS. A simple formula for evaluating the acoustic effect of balconies in protecting dwelling against road traffic noise. Applied Acoustics 2003;64:633-53.

[4] May DN. Freeway noise and high-rise balconies. Journal of Acoustical Society of America 1979; 65(3):699-704.

[5] Gilbert Ph. Une étude sur la protection des habitations et technique du bâtiment. CSTB 1969 [Cahier 901].

[6] Hossam El-Dien H. Acoustic performance of high rise building facades due to its balconies form. In: Naples: Fifth European Conference on noise control; Euronoise. 2003.

[7] Hossam El-Dien H., Woloszyn Ph. Balcony form; an approach to reduce sound pressure level into the building façade. In: Cadiz: Third International Conference on modelling and experimental measurements in acoustics. Acoustics. 2003. pp. 349-58.

[8] Farina A, Brero G. Computer code based on experimental results for acoustical mapping of urban areas. In: Pisa: Proc. of Noise and Planning. 1996.

[9] Farina A. Validation of the Pyramid Tracing algorithm for sound prediction outdoors: comparison with experimental measurements and with the ISO/DIS 9613 standards. Advances in Engineering Software 2000;31/4:241-50. 